Revista Brasileira de Ecoturismo, São Paulo, v.1, n.1, setembro, 2008. ISSN: 1983-9391 - SEÇÃO: ARTIGOS

Lobo, A.S.L.; Perinotto, J.A.J.; Boggiani, P.C. Espeleoturismo no Brasil: panorama geral e perpectivas de sustentabilidade. Revista Brasileira de Ecoturismo, São Paulo, v.1, n.1, 2008, pp.62-83.

\title{
Espeleoturismo no Brasil: Panorama geral e perspectivas de sustentabilidade
}

\section{Heros Augusto Santos Lobo, José Alexandre de Jesus Perinotto, Paulo César Boggiani}

\section{RESUMO}

O espeleoturismo ainda não é considerado um segmento independente das demais atividades de turismo realizadas na natureza. Face ao exposto, o presente trabalho sintetiza os resultados de uma série de pesquisas com o objetivo de apresentar um panorama geral do espeleoturismo no Brasil. Isto se justifica pela necessidade de visualizá-lo de forma autônoma dentro da atividade turística, face às suas especificidades de planejamento e de consumo. As pesquisas realizadas focaram em uma revisão teórico-conceitual e metodológica de diversos trabalhos já publicados no Brasil e no exterior. O resultado ora exposto corresponde a uma base inicial para discussões mais específicas sobre o espeleoturismo no Brasil, considerando as dimensões espeleológica, territorial, política, econômica e ecológica da atividade. Tais resultados validam a existência de um vasto campo de estudos, focado no seu planejamento e gestão. Entretanto, levanta-se o alerta final da necessidade de delimitação pela ótica do mercado, tendo por base também as preferências de consumo dos turistas. Assim, compreendese que novos subsídios poderão ser encontrados para: a consolidação do espeleoturismo enquanto segmento emergente e à parte no arcabouço da segmentação do mercado turístico em um processo de subdivisão do Ecoturismo - enquanto motivação de viagem e especificidade de planejamento e gestão, mas não na forma de execução -; bem como para a formação de políticas públicas para o seu fomento e expansão sustentáveis.

\section{PALAVRAS-CHAVE}

Ecoturismo, Espeleoturismo, Turismo Sustentável.

\section{Speleotourism in Brazil: overview and perspectives for sustainability}

\begin{abstract}
Speleotourism is not yet considered an independent segment of touristic activities conducted outdoors. The present paper thus synthesizes the results of a series of research papers with the objective of presenting a general overview of speleotourism in Brazil. It is justified by the need to conceive it as an autonomous mode of tourism, given the specificities of the planning and consumption involved. The research realized focuses on a theoretical-conceptual and methodological review of various papers already published in Brazil and abroad. The result corresponds to an initial basis for more specific discussions about speleotourism in Brazil, considering the speleological, territorial, political, economic and ecologic dimensions of the activity. These results show the existence of a vast area of study focusing on the planning and management of speleotourism. However, there is a need to delimit from the point of view of the market and the preferences of touristic consumption. Thus, it is understood that new support may need to be found for the consolidation of speleotourism as an emerging segment, a subdivision of ecotourism, so that it can take its part in the outline of the segmentation of the touristic market. Reasons for travel and specificity of planning and management should be considered, but not the means of execution; its encouragement and sustainable expansion should also form part of public policies
\end{abstract}

\section{KEY-WORDS}

Ecotourism, Speleotourism, Sustainable Tourism. 


\section{Introdução}

O Ecoturismo e as demais formas de turismo de contato com a natureza estão entre as atividades turísticas que mais crescem no mundo, devido ao aumento da procura por experiências e vivências em áreas pouco urbanizadas. Com isso, aumenta proporcionalmente a pressão sobre os recursos naturais, em especial as áreas naturais protegidas.

Esta apropriação gera novas posturas e diversos questionamentos sobre o real papel do meio ambiente em uma perspectiva conservacionista, o que vai além do oportunismo mercadológico e da preservação idealizada e distante do ser humano lembrando da concepção do ideário de natureza intocada citado por Diegues (2000).

O interesse do turista, oportunamente chamado de ecoturista, pode ser dividido em duas categorias: a contemplação de formas e elementos da natureza e a sensação de vivência e interação com o meio. Esta segunda categoria ainda se subdivide em outras duas: a interação com vistas à superação - o mote da aventura e a interação metafísica e espiritualizada - motivadora de uma gama diversificada de atividades de turismo religioso e místico.

Para tanto, a apropriação dos elementos naturais é passo decisivo para a ecoturistificação. Cachoeiras, florestas, rios de águas límpidas, montanhas, vulcões, lagos, praias e cavernas estão entre as muitas formas naturais passíveis de gerar atratividade turística, motivando as mais diversas práticas. Destas, destacam-se no presente trabalho as cavernas.

O ambiente subterrâneo, face às suas características geológicas, morfológicas, climáticas e bióticas diferenciadas do meio externo, se coloca como uma das mais complexas situações de manejo de áreas naturais para o turismo. Ao longo dos tempos, as formas de desenvolvimento turístico das cavernas passaram por uma série de adaptações, da super-estruturação e da artificialização total à filosofia do Ecoturismo: grupos menores, limites físicos e comportamentais e a valorização da experimentação em detrimento à mera contemplação e à espetacularização.

Esta evolução pode ser percebida por meio de diversos trabalhos que versam sobre o tema de forma fundamental. Dos primeiros alertas de Cigna (1993) para os cuidados com o manejo do ambiente subterrâneo em função de parâmetros físicoclimáticos aos processos de recuperação ambiental de cavernas degradadas pelo uso humano propostos por Martínez-Arkarazo et.al. (2005). Outros destaques ficam para os trabalhos de Boggiani et.al. (1999), com a experiência pioneira de adaptação da metodologia da Capacidade de Carga de Cifuentes (ARIAS, 1999) para cavernas; de Cigna e Burri (2000), que apresentam um panorama geral do espeleoturismo no mundo, com enfoque nos impactos ambientais negativos e em algumas possibilidades de manejo; de Doorne (2000) ressaltando a importância da capacidade de carga social no processo de gestão de cavernas turísticas; de Cigna (2002), enfatizando e 
propondo os procedimentos mínimos para o manejo de ambientes subterrâneos e de Lobo (2006a) considerando os impactos ambientais do espeleoturismo em função das diversas motivações de visitação às cavernas.

Considerando os aspectos apresentados, o presente trabalho sintetiza os resultados de uma série de pesquisas desenvolvidas com o objetivo de apresentar um panorama geral do espeleoturismo no Brasil. Isto se justifica pela necessidade de se caracterizar cada vez mais o espeleoturismo como segmento autônomo da atividade turística, face às suas especificidades de planejamento e de consumo.

As pesquisas realizadas foram, em sua maioria, fruto de uma revisão teóricoconceitual e metodológica de diversos trabalhos já publicados no Brasil e no exterior, com subsídios do conhecimento prático e da vivência espeleológica dos autores em diversas regiões do país. O enfoque maior está centrado em atividades espeleoturísticas em ambiente terrestre, já que o espeleomergulho é uma atividade ainda pouco desenvolvida no país. A sistematização ora apresentada corresponde a uma base inicial para discussões mais específicas sobre o espeleoturismo no Brasil, considerando as dimensões espeleológica, territorial, política, econômica e ecológica da atividade.

\section{A dimensão espeleológica}

As cavidades naturais subterrâneas são componentes morfológicos de um tipo de relevo que é internacionalmente conhecido como carste. Define-se um relevo como cárstico quando este for construído através de processos de dissolução química, com drenagem predominantemente subterrânea (EPA, 2002). A origem do termo remonta ao século XIX, em uma região que hoje se estende desde a Eslovênia até a Itália. Deriva do termo karst, que por sua vez é uma versão do vocábulo iugoslavo kras, que em sua tradução literal significa "campo de pedras calcárias" (BOGGIANI, 1999; LINO, 2001). Apesar disso, o calcário, bem como as demais rochas carbonáticas, não são as únicas litologias rochosas que formam esse peculiar relevo. Estudos recentes (SPOLADORE, 2006) apontam extensas revisões sobre o conceito de carste, apresentando exemplos em rochas como o arenito e o quartzito - anteriormente classificadas quase que exclusivamente como pseudocarste. Além disso, vale lembrar que mesmo as cavidades naturais desenvolvidas fora de áreas cársticas são passíveis de uso turístico.

A espeleogênese - ou formação das cavidades naturais - acontece tanto no período de formação da rocha, tendo os dutos de lava como melhor exemplo, quanto posteriormente a esta. As que se formam posteriormente à rocha, e principalmente as que são formadas em rochas carbonáticas, são normalmente as mais extensas e ornamentadas. Suas dimensões variam muito, atingindo quilômetros de distância ao se somar todos os seus condutos. A maior cavidade natural já mapeada é a Mamooth 
Cave, nos Estados Unidos, com $580 \mathrm{~km}$ de desenvolvimento. No Brasil, esse título cabe à Toca da Boa Vista, localizada no município de Campo Formoso, BA, com 103 $\mathrm{km}$ já mapeados.

Os espeleotemas são conseqüentes à espeleogênese, detentores de formas e cores variadas, dependendo de seus processos de formação, de sua localização e dos minerais envolvidos em sua composição (HILL; FORTI, 1985). Os mais conhecidos são as estalactites - que pendem do teto - as estalagmites - que se formam no chão, em sentido contrário às estalactites - os travertinos - tipos de represas - e as colunas - originárias da junção entre estalactites e estalagmites.

Este típico ambiente gerado no limiar entre a superfície do planeta e o subsolo é altamente especializado. A falta de luz solar direta na maior parte do meio subterrâneo altera as relações vitais e acarreta na redução da alimentação disponível. Com isso, a circulação de energia dentro do ambiente é diferente, e depende principalmente das correntes de água e ar e da movimentação da fauna cavernícola (TRAJANO \& BICHUETTE, 2006). Em determinadas áreas de uma cavidade natural, face ao confinamento, a presença humana pode gerar mais energia do que a gerada naturalmente em séculos, em função da respiração, calor e partículas deixadas pelas roupas, cabelos e pele (CIGNA, 1993; CIGNA; BURRI, 2000).

O contexto espacial e ambiental apresentado, marcado pelo confinamento, pela escuridão, por organismos por vezes despigmentados e cegos, por um contexto paisagístico ímpar e adverso - sob a ótica antropocêntrica - gera ao mesmo tempo, repulsa e atratividade no ser humano (FIGUEIREDO, 1998; TRAVASSOS et.al., 2007). Face a esta mistura de sensações de incômodo e conforto que o espeleoturismo se firma como uma proposta diferenciada de Ecoturismo.

\section{A dimensão territorial no Brasil}

A presente análise é espacializada no território nacional a partir da identificação de suas cavernas turísticas. Para sua delimitação, primeiramente foram compilados os trabalhos publicados por Figueiredo (1998), Marra (2001), Scaleante (2005) e Lino (s.d.). Nesta fase foram consideradas apenas as cavernas citadas pelos autores, pois alguns estudos mencionavam o nome de uma Unidade de Conservação com muitas cavernas, sem, no entanto, relacioná-las. Foram consideradas, de forma indistinta, as cavernas visitadas sob as mais diversas motivações, com especial destaque à contemplação, à aventura e à religião. Também foram consideradas as cavidades que são visitadas regularmente, apesar de não possuírem plano de manejo ou instrumentos e medidas legais de controle da visitação. Ao todo, foram identificadas 97 cavidades naturais abertas a algum tipo de visitação turística (Tabela $1)$. 
Apesar da abrangência dos estudos mencionados, diversas outras cavernas espeleoturísticas não foram mencionadas. Os motivos para estas não terem sido citados nos estudos anteriores podem variar muito, e consideram-se as seguintes hipóteses: ocorrências em áreas cársticas em outras litologias rochosas diferentes do calcário (arenito, quartzito, gnaisse etc); muitas delas não são "oficialmente" turísticas, por não possuírem planos de manejo e instrumentos legais que orientem a visitação, embora sejam regularmente visitadas; muitas estão em áreas que foram citadas de forma ampla nos estudos anteriores, como o Parque Estadual Turístico do Alto Ribeira e a Chapada Diamantina.

Tabela 1 - Compilação bibliográfica das cavidades espeleoturísticas brasileiras

\begin{tabular}{|l|l|}
\hline \multicolumn{1}{|c|}{ Cavidade Natural e UF } & \multicolumn{1}{c|}{ Cavidade Natural e UF } \\
\hline 1. Refúgio do Maroaga - AM & 26. Gruta dos Ecos - GO \\
\hline 2. Gruta do Convento (Salitre) - BA & 27. Gruta Aroe Jarí - MT \\
\hline 3. Gruta dos Brejões - BA & 28. Gruta do Lago Azul - MS \\
\hline 4. Gruta do Lapão - BA & 29. Buraco das Araras - MS \\
\hline 5 e 6. Lapa Doce I e II - BA & 30. Abismo Anhumas - MS \\
\hline 7. Gruta da Pratinha - BA & 31. Gruta de São Miguel - MS \\
\hline 8. Gruta Azul - BA & 32. Buraco das Abelhas - MS \\
\hline 9. Buraco do Cão - BA & 33. Gruta do Maquiné - MG \\
\hline 10. Poço Encantado - BA & 34. Gruta Rei do Mato - MG \\
\hline 11. Poço Azul - BA & 35. Gruta da Lapinha - MG \\
\hline 12. Gruta do Padre - BA & 36. Gruta dos Palhares - MG \\
\hline 13. Lapa da Mangabeira - BA & 37. Gruta do Tamboril - MG \\
\hline 14. Lapa do Bom Jesus - BA & 38. Gruta Casa de Pedra - MG \\
\hline 15. Gruta da Lapinha - BA & 39. Lapa Nova - MG \\
\hline 16. Gruta da Paixão - BA & 40. Lapa Velha - MG \\
\hline 17. Gruta Torrinha - BA & 41. Gruta Carimbado I - MG \\
\hline 18. Gruta de Ubajara - CE & 42. Gruta Morena - MG \\
\hline 19. Gruta do Limoeiro - ES & 43. Gruta do Janelão - MG \\
\hline 20. Lapa da Angélica - GO & 44. Lapa dos Desenhos - MG \\
\hline 21. Lapa da Terra Ronca - GO & 45. Gruta da Igrejinha - MG \\
\hline 22. Gruta Escaroba - GO & 46. Gruta Bonita - MG \\
\hline 23. Buraco das Araras - GO & 47. Lapa dos Cascudos - MG \\
\hline 24. Buraco do Inferno - GO & 48. Gruta Pacas - MG \\
\hline 25. Gruta Jaboticaba - GO & 49. Gruta Tuncis - MG \\
\hline
\end{tabular}

continua... 


\begin{tabular}{|l|l|}
\hline \multicolumn{1}{|c|}{ Cavidade Natural e UF } & \multicolumn{1}{c|}{ Cavidade Natural e UF } \\
\hline 50, 51 e 52. Gruta Cascata I, II e III - MG & 75. Caverna Santana - SP \\
\hline 53. Grua Irmãos Piriás - MG & 76. Caverna Morro Preto - SP \\
\hline 54. Gruta Balet - MG & 77. Gruta do Couto - SP \\
\hline 55. Gruta Poções - MG & 78. Caverna Água Suja - SP \\
\hline 56. Gruta do Baú - MG & 79. Caverna Laje Branca - SP \\
\hline 57. Gruta do Sumidouro - MG & 80. Caverna Alambari de Baixo - SP \\
\hline 58. Gruta Carrancas - MG & 81. Gruta do Chapéu - SP \\
\hline 59. Gruta Toca - MG & 82 e 83. Gruta Chapéu Mirim I e II - SP \\
\hline 60. Gruta Zilda - MG & 84. Gruta das Aranhas - SP \\
\hline 61. Gruta do Salitre - MG & 85. Gruta Laboratório II - SP \\
\hline 62. Gruta do Éden - MG & 86. Caverna do Betari - SP \\
\hline 63. Gruta dos Caboclos - MG & 87. Gruta da Barreira - SP \\
\hline 64. Lapa Grande - MG & 88. Gruta Arataca - SP \\
\hline 65. Lapa dos Troncos - MG & 89. Gruta da Pescaria - SP \\
\hline 66. Gruta da Lancinha - PR & 90. Gruta Colorida - SP \\
\hline 67. Conjunto Jesuítas/Fadas - PR & 91. Gruta da Mãozinha - SP \\
\hline 68. Gruta Bacaetava - PR & 92. Gruta dos Paiva - SP \\
\hline 69 e 70. Furnas de Vila Velha I e II - PR & 93. Gruta Santa Luzia - SP \\
\hline 71. Furna Buraco do Padre - PR & 94. Gruta do Tatu - SP \\
\hline 72. Gruta Botuverá - SC & 95. Gruta do Fogo - SP \\
\hline 73. Gruta Itambé - SP & 96. Gruta dos Martins - RN \\
\hline 74. Caverna do Diabo - SP (FIGURA 1) & 97. Furna Feia - RN \\
\hline
\end{tabular}

\section{...Continuação.}

Compilado pelos autores a partir de: Figueiredo (1998); Marra (2001); Scaleante (2005) e Lino (s.d.).

Os dados encontrados foram ampliados por pesquisas de campo, com os resultados apresentados na Tabela 2. 
Tabela 2 - Outras cavernas espeleoturísticas brasileiras

\begin{tabular}{|c|c|}
\hline Cavidade Natural e UF & Cavidade Natural e UF \\
\hline 98. Gruta do Batismo - AM & 128. Gruta do Belmiro - RJ \\
\hline 99. Gruta de São Bernardo - GO & 129. Gruta Luís Fernandes - RJ \\
\hline 100. Gruta do Urucuia - GO & 130. Gruta dos Morcegos - RJ \\
\hline 101. Gruta da Lagoa Azul - MT & 131. Gruta Bernardo de Oliveira - RJ \\
\hline 102. Lagoa Misteriosa - MS & 132. Gruta Gabriela - RJ \\
\hline 103. Gruta do Mimoso - MS & 133. Gruta Paulo e Virgínia - RJ \\
\hline 104. Gruta do Urubú-Rei - MS & 134. Gruta da Surucucu - RJ \\
\hline 105. Gruta da Bruxa - MG & 135. Gruta do Eleutério - RJ \\
\hline 106. Gruta São Tomé - MG & 136. Gruta do Acaiá - RJ \\
\hline 107. Gruta do Sobradinho - MG & 137. Gruta do Panelão - RS \\
\hline 108. Gruta do Labirinto - MG & 138. Gruta do Parque - SP \\
\hline 109. Gruta da Cachoeira - MG & 139. Gruta do Zé Maneco - SP \\
\hline 110. Gruta dos Três Arcos - MG & 140. Gruta do Anjo - SP \\
\hline 111. Gruta do Fugitivo - MG & 141. Gruta Jane Mansfield - SP \\
\hline 112. Gruta do Coelho - MG & 142. Gruta do Minotauro - SP \\
\hline 113. Gruta dos Viajantes - MG & 143 a 145. Gruta do Rolado I, II e III - SP \\
\hline 114. Gruta dos Gnomos - MG & 146. Gruta Lágrima do Tempo - SP \\
\hline 115. Ponte de Pedra - MG (FIGURA 2) & 147. Gruta da Glória - SP \\
\hline 116. Gruta do Monjolinho - MG & 148. Gruta do Cafezal - SP \\
\hline 117. Lapa do Îndio - MG & 149. Gruta Temimina - SP \\
\hline 118. Lapa do Boquete - MG & 150. Gruta do Lago Suspenso - SP \\
\hline 119. Arco do André - MG & 151. Gruta Sítio Novo - SP \\
\hline 120. Lapa do Carlúcio - MG & 152. Gruta Laboratório I - SP \\
\hline 121. Lapa do Rezar - MG & 153. Buraco do André - SP \\
\hline 122. Dolina dos Macacos - MG & 154. Gruta do Ouro Grosso - SP \\
\hline 123. Gruta Antônio Pereira - MG & 155. Gruta Desmoronada - SP \\
\hline 124. Gruta do Monge - PR & 156. Gruta dos Sonhos - SP \\
\hline 125. Gruta Olhos d'Água - PR & 157. Gruta do Jeremias - SP \\
\hline 126. Gruta do Pinhalzinho - PR & 158. Gruta Espírito Santo - SP \\
\hline 127. Gruta do Capim Açu - PE & 159. Gruta Monjolinho - SP \\
\hline
\end{tabular}

Continua... 
...Continuação.

\begin{tabular}{|l|l|}
\hline 160. Gruta da Marreca - SP & 167. Gruta Duas Bocas - SP \\
\hline 161. Gruta da Paçoca - SP & 168. Gruta Itambé - SP \\
\hline 162. Gruta Casa Velha - SP & 169. Gruta do Paredão - SP \\
\hline 163. Caverna Crystal - SP & 170. Gruta do Edgar - SP \\
\hline 164. Gruta do Fazendão - SP & 171. Abrigo da Glória - SP \\
\hline 165 e 166. Gruta Captação I e II - SP & 172. Boca do Sapo - SP \\
\hline
\end{tabular}

Fonte: pesquisa dos autores

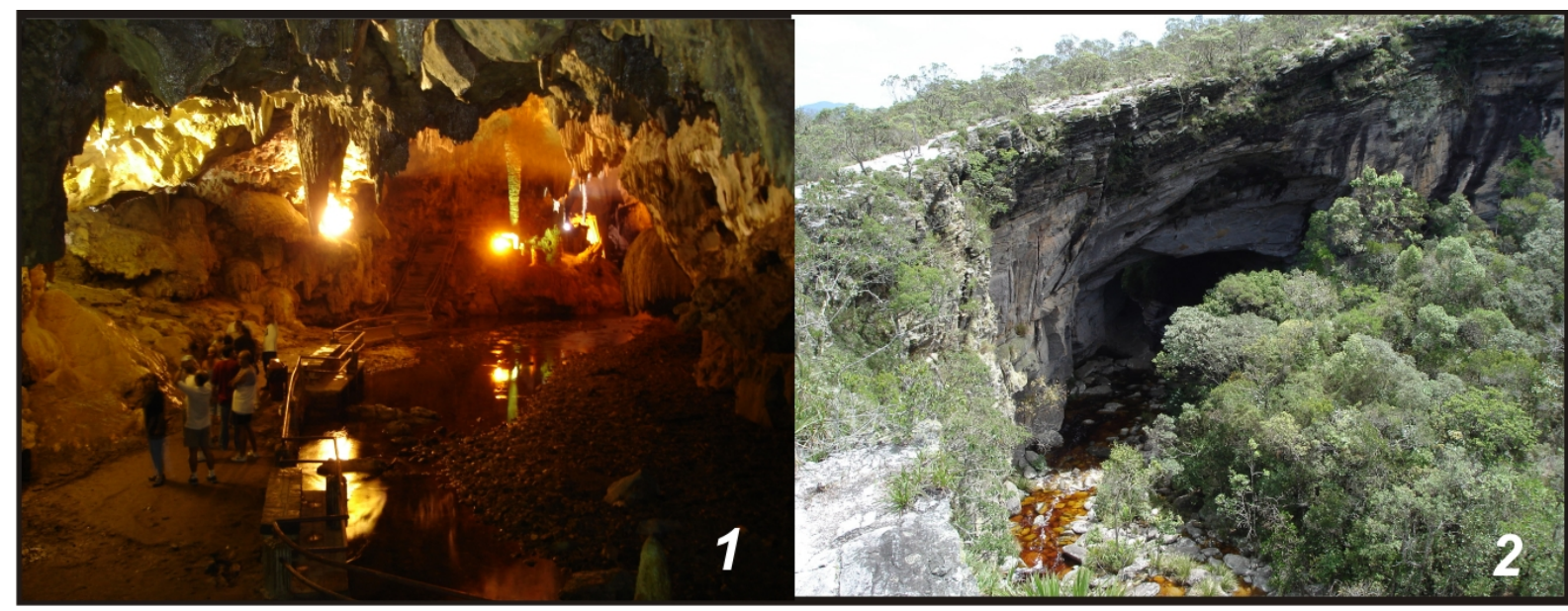

Figuras: 1 - Caverna do Diabo, no Parque Estadual Caverna do Diabo, SP, com iluminação artificial e estruturas voltadas ao turismo de massa; 2 - Caverna da Ponte de Pedra, no Parque Estadual de Ibitipoca, MG, que tem particularidades como a cor de suas águas e o fato de ser formada em quartzito. Fotos de Heros A. S. Lobo

Com isso, eleva-se para 175 o total de cavernas com algum tipo de visitação turística no Brasil - lembrando que muitas das cavernas de ambas as listas estão temporariamente fechadas para a visitação, em função de determinações legais para a elaboração de seus respectivos instrumentos de manejo. Estes números ainda são considerados preliminares, demonstrando a necessidade de uma pesquisa mais ampla e específica sobre o tema. Destacam-se pela quantidade os estados de São Paulo com 58 cavernas turísticas, Minas Gerais, com 52 e Bahia com 16.

Essa compilação é dificultada pela própria abrangência territorial do país, aliada à existência de muitas cavernas visitadas em contextos regionais, mas que não são de amplo conhecimento junto à comunidade espeleológica nacional. Um outro aspecto a ser considerado em pesquisas futuras, necessário para definir melhor 0 foco destes tipos de levantamento, é a diferença entre cavernas visitadas e o 
espeleoturismo institucionalizado. Tentativas neste sentido, de identificar uma chave para a sistematização e classificação de cavernas turísticas já vêm sendo realizadas há algum tempo, como se observa por meio dos trabalhos de Lino (1988), Marra (2001), Lobo (2007), Lobo e Asmus (2007) e Lobo et.al. (2007). Todavia, um critério mais universal e aplicável em todo o território nacional ainda precisa ser feito, de forma a contribuir no processo de planejamento e gestão das cavernas turísticas brasileiras. Sem dúvida, este trabalho vai além da fronteira técnico-científica ora em questão.

\section{A dimensão política}

O espeleoturismo não se encontra no cerne da discussão sobre as políticas públicas de turismo no Brasil. Embora a fragilidade deste ambiente justifique uma especial atenção quanto aos mecanismos reguladores que contribuam para conciliar o uso sustentável com a conservação, poucas leis e diretrizes versam diretamente sobre o tema.

A dimensão política que rege o espeleoturismo pode ser dividida em três categorias básicas: as leis que contribuem para a conservação das cavidades naturais; os instrumentos legais que determinam o planejamento, por meio dos planos de manejo espeleológicos - PMEs -; e as normas de conduta, orientando os espeleoturistas nas boas práticas e nos limites sugeridos.

Do ponto de vista legal, excetuando-se as leis e demais instrumentos reguladores estaduais, distritais e municipais, podem ser ressaltados quatro marcos expressivos que, de forma direta ou indireta, beneficiam as práticas espeleoturísticas. O primeiro deles é a Constituição Federal de 1988, que em seus artigos vinte e 216 faz menção às cavidades naturais como parte do conjunto de bens pertencentes à união. Esta medida orienta seu uso, que fica condicionado à necessidade de concessões por parte dos órgãos públicos responsáveis.

O segundo ponto de destaque é a Lei n. 9.985 de 18 de julho de 2000, o Sistema Nacional de Unidades de Conservação. O SNUC, forma como a lei ficou conhecida, apresenta suas contribuições ao espeleoturismo por meio das possibilidades de uso sustentável de cavidades naturais localizadas em áreas legalmente protegidas para fins ecoturísticos, as Unidades de Conservação da Natureza - UCs. Estas podem ser divididas em UCs de Preservação Integral e de Uso Sustentável, sendo o Ecoturismo e a Educação Ambiental permitidos em algumas categorias de UCs em ambos os casos. Com isso, já determina a base conceitualcomportamental que deve reger o tipo de turismo a ser realizado nestas cavidades naturais. Algumas áreas com grande concentração de cavernas no país já foram transformadas em UCs, atuando, desta forma, em sua proteção e em seu uso sustentável. Exemplos disso - alguns anteriores à existência do SNUC - são o 
Parque Estadual Turístico do Alto Ribeira, no Estado de São Paulo; o Parque Nacional da Serra da Bodoquena, no Mato Grosso do Sul; o Parque Nacional de Ubajara, no Ceará; o Parque Nacional Cavernas do Peruaçu, em Minas Gerais.

Estas premissas ganham ainda mais força a partir da Resolução CONAMA $n^{\circ}$ 347, que dispõe sobre a proteção do patrimônio espeleológico, considerando a necessidade de licenciamento ambiental para empreendimentos em áreas com ocorrência de cavidades naturais e o princípio da precaução na gestão das mesmas. Desta forma, a resolução define alguns critérios para o uso e a conservação de cavernas. Em seu artigo $6^{\circ}$, coloca que os empreendimentos turísticos que utilizem o patrimônio espeleológico deverão respeitar o Plano de Manejo Espeleológico - PME , o qual deve ser aprovado pelo IBAMA (CONAMA, 2004). De fato, os PMEs são o instrumento de referência para o uso sustentável das cavidades naturais para fins turísticos. Neles, são feitos estudos prévios considerando os meios bióticos, abióticos, os aspectos sociais e econômicos, da cavidade natural e de seu entorno imediato. Os PMEs definem, entre outros, as formas e os limites de uso permitidos, justificando-os por meio de estudos científicos multidisciplinares.

Quanto ao espeleoturismo de aventura, duas iniciativas em nível nacional contribuem para sua regulamentação. A primeira delas, partindo do Ministério do Turismo, diz respeito às normas sobre o Turismo de Aventura no Brasil. No caso do espeleoturismo, já se encontra aprovada a norma de competências para condutores. A outra norma, de especificação do produto, ainda não foi finalizada. Esta tem sido alvo de críticas da comunidade espeleológica nacional, dado que incentiva o uso de reatores de carbureto. Estudos científicos comprovam que estes causam impactos negativos no ambiente em diversos casos, ao que se entende que propor seu uso em todas as cavidades naturais abertas ao espeleoturismo de aventura foge do princípio básico da precaução. A segunda iniciativa partiu do próprio IBAMA, por meio da Instrução Normativa n. 100, de 5 de junho de 2006. Esta criou o Conselho Especializado em Mergulho em Cavernas - CEMEC -, de caráter consultivo, com a finalidade de auxiliar nas análises e autorizações relacionadas ao mergulho em cavernas no Brasil. O documento também prevê o uso turístico destas cavidades inundadas, apontando em linhas gerais alguns limites técnicos e outros relacionados à segurança dos praticantes.

Além disso, três Projetos de Lei sobre o patrimônio espeleológico tramitam no Congresso Nacional - 5.071/1990, 2.832/2003 e 2.047/2007 - (RASTEIRO, 2008a) o que demonstra a desarticulação política em torno do tema e a probabilidade de que interesses diversos e dispersos, que vão além do patrimônio, podem estar sendo privilegiados na esfera legislativa.

Todavia, as diretrizes e os instrumentos legais mencionados não são suficientes para uma boa política conservacionista das cavernas no Brasil. A falta de uma lei específica prejudica a execução sustentável do espeleoturismo, já que, conforme Lobo et.al. (2006), os instrumentos legais até então existentes versam tão 
somente à preservação das cavernas. Alia-se a essa situação o descaso e o lapso de diversos órgãos gestores - públicos e privados - de cavernas turísticas no Brasil, o que tem ocasionado o fechamento temporário de atrativos, comprometendo toda a cadeia produtiva do turismo e as comunidades locais envolvidas. Como exemplos, citam-se o fechamento da Gruta do Lago Azul em Bonito, MS, em Agosto de 2006 e de todas as cavernas abertas ao uso público nos Parques Estaduais Intervales, Caverna do Diabo e Turístico do Alto Ribeira, SP, em 2008.

Para se ter uma idéia do descompasso entre o fluxo espeleoturístico e as políticas de manejo conservacionista, a Tabela 3 apresenta todas as cavernas brasileiras que já possuem o seu PME elaborado e aprovado pelos órgãos competentes.

Tabela 3 - Cavernas com PME elaborado e aprovado no Brasil

\begin{tabular}{|l|l|}
\hline \multicolumn{1}{|c|}{ Nome } & \multicolumn{1}{c|}{ Localização } \\
\hline Refúgio do Moroaga & Presidente Figueiredo - AM \\
\hline Gruta do Batismo & Presidente Figueiredo - AM \\
\hline Poço Encantado & Itaeté - BA \\
\hline Gruta dos Ecos & Cocalzinho - GO \\
\hline Gruta do Lago Azul & Bonito - MS \\
\hline Gruta Nossa Senhora Aparecida & Bonito - MS \\
\hline Gruta de São Miguel & Bonito - MS \\
\hline Abismo Anhumas & Bonito - MS \\
\hline Gruta Bacaetava & Colombo - PR \\
\hline Gruta da Lancinha & Rio Branco do Sul - PR \\
\hline Gruta Botuverá & Botuverá - SC \\
\hline
\end{tabular}

Fonte: Rasteiro (2008-b) e pesquisas dos autores

A situação é no mínimo curiosa, já que os Estados que possuem o maior número de cavernas visitadas no país, Minas Gerais e São Paulo, não figuram na lista de cavernas com PMEs aprovados. 


\section{A dimensão Econômico-Ecológica}

Os impactos do turismo correspondem às modificações que a atividade gera onde se desenvolve, sob diversos níveis de intensidade e natureza (RUSCHMANN, 2004). Quanto ao espeleoturismo, Cigna e Burri (2000) afirmam que, de forma geral, seus impactos negativos podem ser divididos em: conseqüências diretas e indiretas dos sistemas de iluminação; o particulado levado para dentro das cavernas nas roupas, cabelos e corpo; os impactos físicos; e as alterações nas taxas de gás carbônico $\left(\mathrm{CO}_{2}\right)$. Sobre este último grupo, Song et.al. (2000) atestaram que apenas a respiração dos turistas já é suficiente para alterar o ambiente cavernícola. Isso pode ser agravado pelo uso de carbureteiras. Apesar de suas vantagens para os condutores e turistas, as conseqüências para o ambiente cavernícola são desastrosas, pois a queima do acetileno gera o danoso $\mathrm{CO}_{2}$. Além disso, as carbureteiras geram calor, fator pesquisado por Scaleante (2003) na Caverna de Santana, PETAR. Este autor observou que o calor gerado promove grandes alterações nas taxas de umidade e na temperatura do ambiente.

Os impactos ambientais do turismo em cavernas integram a própria essência da atividade, já que é praticamente impossível adentrar no ambiente subterrâneo sem Ihe causar algum tipo de alteração. O que vai mudar é a forma de utilização das cavernas, que pode ser mais ou menos danosa em função das propostas de visitação e das práticas turísticas adotadas. Atividades turísticas de massa, para fins religiosos, recreativos ou contemplacionais, tendem a ser mais danosas pelo volume de visitação do que aquelas com uma roupagem mais sustentável, para fins de educação, contemplação ou aventura. Mas a postura do visitante também é decisiva nesse aspecto.

No Brasil, o histórico da visitação turística de cavernas se iniciou por fins religiosos, provavelmente em 1690, em Bom Jesus da Lapa, na Bahia (FIGUEIREDO, 1988). Atualmente, a Lapa da Igreja é totalmente modificada, em função da construção de um templo em seu interior. Além desta, muitas outras cavernas brasileiras recebem visitação por motivos religiosos, como a Gruta Terra Ronca, GO, a Gruta Antônio Pereira, MG e a Gruta da Barreira, SP (LOBO et.al., 2007).

Em tempos mais recentes, a partir dos anos sessenta do século passado, iniciam-se diversas ações de estruturação turística em cavernas no Brasil para fins de visitação em massa - fruto da popularização do turismo no país e de exemplos de cavernas hiper-estruturadas no exterior. A maior herança sob o ponto de vista dos danos ambientais ao patrimônio advinda dessa época são as estruturas de acesso e a iluminação artificial com luzes incandescentes que permanecem acesas o dia todo caso da Caverna do Diabo, SP e da Gruta de Maquine, MG. Este modelo de visitação, considerado de vanguarda para a época, não tem mais lugar nas políticas de manejo conservacionista dos dias atuais, quando se busca cada vez mais conciliar o uso do patrimônio espeleológico com a sua manutenção para as gerações futuras e para fins 
de conservação ambiental.

A grande virada nesta forma de pensar o turismo em cavernas no Brasil pode ser decorrente de alguns marcos históricos, como o fortalecimento do movimento ambientalista, a propagação do ideário de desenvolvimento sustentável à partir da ECO 92, a criação do Centro Nacional de Estudo, Proteção e Manejo de Cavernas CECAV - no Instituto Brasileiro do Meio Ambiente - IBAMA - em 1997 e a difusão de práticas modernas de manejo adotadas no exterior em meio à técnicos da área de manejo no país. Não pode deixar de ser mencionado o alerta de muitos guias, condutores, espeleístias, espeleólogos quanto aos impactos gerados pelo turismo em diversas regiões do país, o que ampliou a preocupação dos setores diretamente envolvidos com o espeleoturismo com o uso sustentável das cavernas.

O caso mais representativo que ilustra esta mudança de postura é a região da Serra da Bodoquena, com as grutas de Bonito, MS (Figuras 3 a 7). A tentativa de disciplinar a atividade espeleoturística na região é anterior até mesmo aos fatos citados, podendo ter como marco temporal e divisor de águas o projeto Grutas de Bonito, que apresenta diretrizes básicas para o manejo conservacionista das cavernas da região (LINO et.al., 1984). Na mesma região, outros fatores externos ao espeleoturismo também concorreram para auxiliar nesta regulamentação, como a criação do voucher único, a obrigatoriedade dos guias locais no passeio e a criação do Conselho Municipal de Turismo - COMTUR -, que, até onde se sabe, é pioneiro no país (LOBO, 2006).

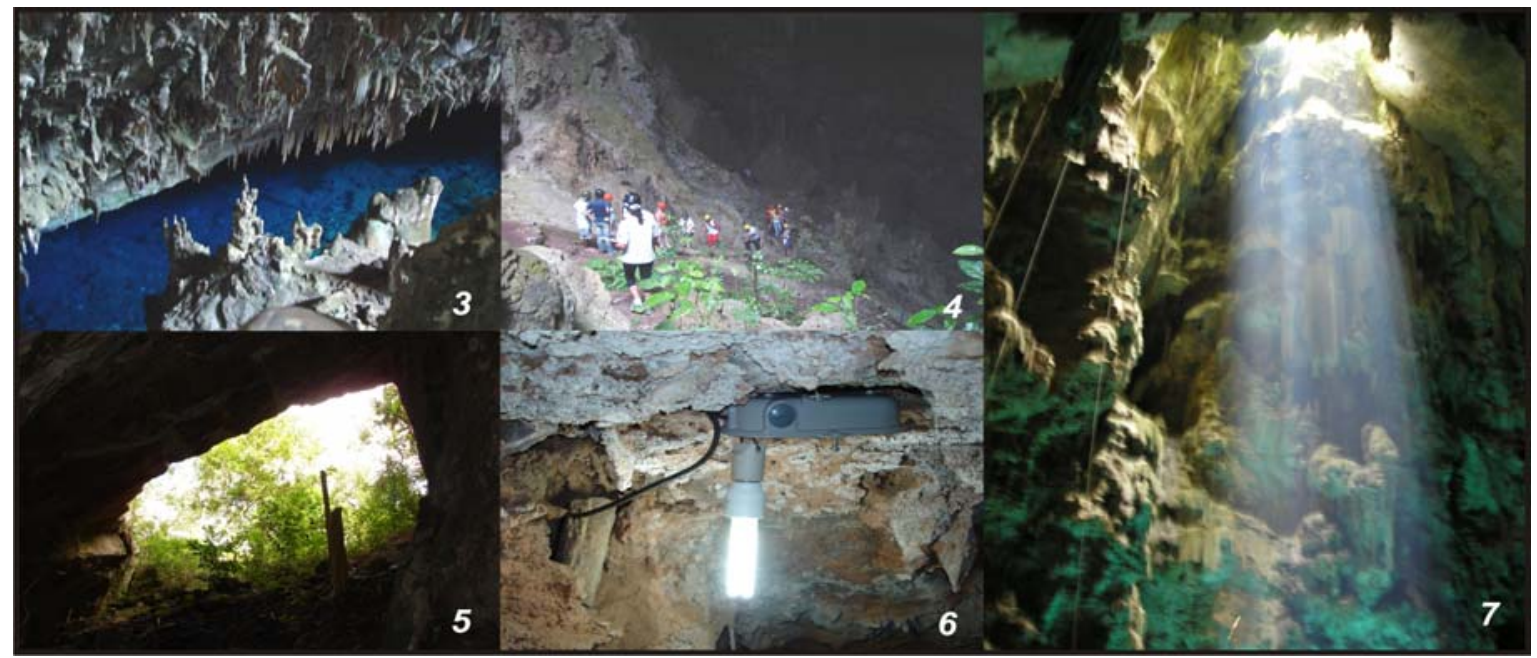

Figuras: 3 - Visão lateral da Gruta do Lago Azul; 4 - A falta de um corrimão no percurso de visitação é um ponto polêmico na Lago Azul. Alega-se que a sua presença poderia causar prejuízo estético ao patrimônio. Por outro lado, a sua ausência aumenta a dificuldade de acesso de pessoas menos preparadas fisicamente e idosos - grupos comuns no local; 5 - Pórtico de entrada da Gruta de São Miguel, e em detalhe (6), luz fluorescente compacta instalada em seu interior; 7 - Visão interna do pórtico de entrada do Abismo Anhumas. Fotos 3 a 6 - Heros A. S. Lobo; 7 - Anderson dos S. Amorim. 
O processo de regulamentação do espeleoturismo em Bonito encontra continuidade no trabalho de Labegallini (1995), com uma proposta de uso para a Gruta do Lago Azul, parcialmente aproveitada nos trabalhos de Estudo de Impacto Ambiental-Relatório de Impacto Ambiental - EIA-RIMA - da referida caverna, iniciados em 1999 (BOGGIANI et.al., 2002). Na atualidade, as outras duas cavernas abertas ao uso público em Bonito - o Abismo Anhumas e a Gruta de São Miguel possuem também seus instrumentos de manejo aprovados pelo CECAV, conforme já apresentado na Tabela 3. No caso da Gruta de São Miguel, até mesmo a iluminação fixa artificial foi mantida, mas com lâmpadas frias e com circuitos setorizados de visitação, o que prova que nem todas as cavernas com projetos mais sustentáveis e menos danosos ao meio cavernícola precisam ser necessariamente dirigidas à um público mais aventureiro ou ao ecoturista mais extremo.

Mesmo com posturas e propostas de manejo mais adequadas, o espeleoturismo ainda causa impactos ambientais no meio. Para ilustrar de forma geral a abrangência destes impactos, Lobo (2006a) desenvolveu um diagrama de causa e conseqüência que considera as diversas formas segmentadas do turismo e seus respectivos impactos mais comuns (Figura 4).

Conhecer os impactos ambientais negativos pode ser a chave para um planejamento e gestão sustentáveis no espeleoturismo. Tendo-se o conhecimento prévio das conseqüências indesejáveis da visitação, muitas delas podem ser evitadas tanto na fase de planejamento quanto de gestão do turismo. Todavia, é importante não perder de vista que os impactos ambientais causados pelo espeleoturismo em hipótese alguma serão totalmente mitigados. Na melhor das hipóteses, as técnicas e métodos de planejamento e gestão poderão contribuir para sua diminuição e controle parcial. Assim, é preciso considerar o monitoramento constante da visitação, sobretudo porque em diversos lugares, esta ocorre em grande escala.

A importância econômica do turismo realizado em cavidades naturais em algumas localidades do Brasil é bastante expressiva. Diversos são os destinos turísticos que têm nelas o seu foco de atratividade, principal ou secundário. Esta constatação é importante para que se possa obter uma base sobre a importância socioeconômica do espeleoturismo, já que não existem pesquisas específicas sobre este segmento realizadas em âmbito nacional. Parques Nacionais, como o de Ubajara (CE); Estaduais como o PETAR, Intervales e Jacupiranga (todos em SP); e outras Unidades de Conservação como o Monumento Natural Gruta do Lago Azul (MS), estão entre as mais expressivas áreas de visitação turística de cavernas no país. Além destes, destaca-se também o Circuito das Grutas, em Minas Gerais, com diversas cavidades naturais abertas à visitação englobando diferentes possibilidades de uso.

Para fornecer uma referência quanto à importância conferida às cavernas no contexto do turismo em suas respectivas regiões, a Tabela 4 apresenta dados sobre os fluxos anuais de visitação das Grutas do Lago Azul, São Miguel e do Abismo Anhumas, localizados em Bonito, MS, bem como do PETAR-SP e da Gruta de Maquiné, localizada em Cordisburgo, MG. 
Lobo, H.A.S., Perinotto, J.A. de J., Boggiani , P.C.

\begin{tabular}{|c|c|c|c|c|c|c|c|c|}
\hline \multicolumn{9}{|c|}{ FATORES CONDICIONANTES DOS IMPACTOS } \\
\hline \multirow[b]{2}{*}{$\begin{array}{l}\text { SEGMENTOS } \\
\text { DO TURISMO }\end{array}$} & \multicolumn{3}{|c|}{ ESTRUTURRS, FETORIAS EEQUIPAMENTOS } & \multicolumn{5}{|c|}{ PROALEMASG ERROOS NO PROCESSO DE VISTRC. } \\
\hline & $\begin{array}{l}\text { ORATÓRIOS, } \\
\text { ALTARES, } \\
\text { IIREAASE } \\
\text { AFINS } \\
\text { (A) }\end{array}$ & \begin{tabular}{|c|} 
ACESSOE \\
SEGURANCA \\
(B) \\
\end{tabular} & $\begin{array}{l}\text { ILUMNNACAO } \\
\text { ARTIFICIAL } \\
\text { (FIXAEOUU } \\
\text { MOOVEL) } \\
\text { (C) }\end{array}$ & $\begin{array}{l}\text { POSTURA } \\
\text { DO } \\
\text { TURISTA } \\
\text { (D) }\end{array}$ & \begin{tabular}{|c|} 
POEIRAE \\
FULIGBM \\
(E) \\
\end{tabular} & $\begin{array}{l}\text { MATERRIA } \\
\text { ORGANACA } \\
(\text { F }\end{array}$ & $\begin{array}{l}\text { CALOR- } \\
\text { CORPOE } \\
\text { FONTES } \\
\text { DELIZ } \\
(G) \\
\end{array}$ & $\begin{array}{l}\mathrm{CO}_{3} \\
(H)\end{array}$ \\
\hline $\begin{array}{l}\text { Turismo } \\
\text { Religioso }\end{array}$ & $x$ & $x$ & $x$ & $x$ & $x$ & $x$ & $x$ & $x$ \\
\hline $\begin{array}{l}\text { Turismo de } \\
\text { Massa }\end{array}$ & - & $x$ & $x$ & $x$ & $x$ & $x$ & $x$ & $x$ \\
\hline $\begin{array}{l}\text { Turismo de } \\
\text { Aventural } \\
\text { Ecoturismo }\end{array}$ & - & - & $x$ & $x$ & $x$ & $x$ & $x$ & $x$ \\
\hline \multicolumn{9}{|c|}{$\begin{array}{l}\text { Fluxo e principais relaçôes diretas de causa e efito entre os fatores condicionantes dos impactos e } \\
\text { as consequêencias para } 0 \text { ambiente cavernicola }\end{array}$} \\
\hline$A, B, D$ & & , E, G & $\mathrm{C}$ & & C, & & & \\
\hline $\begin{array}{c}\text { DANNFICACÃO } \\
\text { EIOU } \\
\text { DESTRUIÇÄO } \\
\text { DAS } \\
\text { FORMACOÓES E } \\
\text { DO MEIO FÍSICO }\end{array}$ & $\begin{array}{l}\text { ALTER } \\
\text { COMF } \\
\text { EIOU ES } \\
\text { FISICO } \\
\text { ESPEL }\end{array}$ & $\begin{array}{l}\text { ACCONESNA } \\
\text { POSICANO } \\
\text { STRUTURA } \\
\text { D-QUIMICA } \\
\text { DOS } \\
\text { EOTEMAS }\end{array}$ & $\begin{array}{l}\text { SURGIM } \\
\text { DE PLAN } \\
\text { MUSC } \\
\text { DENTR } \\
\text { CAVID }\end{array}$ & $\begin{array}{l}\text { NTO } \\
\text { ASE } \\
\text { S } \\
\text { DA } \\
\text { DE }\end{array}$ & $\begin{array}{r}\text { ALTERAÇ } \\
\text { HÁAITO } \\
\text { COMPORT } \\
\text { DAFA }\end{array}$ & $\begin{array}{l}\text { DES NOS } \\
\text { SE NO } \\
\text { AMENTO } \\
\text { UNA }\end{array}$ & $\begin{array}{l}\text { ALTERA } \\
\text { PARA } \\
\text { AMEIEN } \\
\text { UMMIDA } \\
\text { TEMPE }\end{array}$ & $\begin{array}{l}\text { EES NOS } \\
\text { EROS } \\
\text { IS }\left(\mathrm{CO}_{2,}\right. \\
\text { DO AR, } \\
\text { ATURA) }\end{array}$ \\
\hline & ONSEQÜ & JÊNCIAS & PARA O & AMB & NTE CA & VERNÍ & OLA & \\
\hline & & J5 de & 5 II & & yue & & & \\
\hline
\end{tabular}

Figura 4 - Relações de causa e conseqüência dos impactos ambientais do espeleoturismo nos meios biótico e abiótico das cavernas (LOBO, 2006a, p. 8) 
Tabela 4 - Fluxo de visitação de algumas cavidades naturais espeleoturísticas

\begin{tabular}{|l|l|r|r|r|}
\hline \multicolumn{1}{|c|}{ Caverna } & \multicolumn{1}{c|}{ Localização } & \multicolumn{1}{c|}{2003} & \multicolumn{1}{c|}{2004} & \multicolumn{1}{c|}{2005} \\
\hline Abismo Anhumas & Bonito, MS & 738 & 909 & 720 \\
\hline Gruta do Lago Azul & Bonito, MS & 48.364 & 44.014 & 45.116 \\
\hline Gruta de São Miguel & Bonito, MS & 11.894 & 8.950 & 5.756 \\
\hline Gruta de Maquiné & Cordisburgo, MG & 38.636 & 41.241 & - \\
\hline $\begin{array}{l}\text { PETAR - Núcleo Santana } \\
\text { (Cavernas: Santana, Morro } \\
\text { Preto, Couto, Água Suja e } \\
\text { Cafezal) }\end{array}$ & Iporanga, SP & 34.744 & 25.617 & - \\
\hline
\end{tabular}

Fonte: Lobo (2005, 2006-b); Nogueira (2006).

Como se observa, os dados apontam para valores expressivos. Em lugares como o PETAR e a Gruta de Maquiné, o montante de turistas recebidos corresponde quase que a totalidade dos turistas recebidos em suas respectivas regiões. No caso das grutas de Bonito, não existem pesquisas que demonstrem a sobreposição ou diferenciação dos turistas nos três atrativos analisados. Entretanto, conforme estimativas do poder público local, o município recebe em média 70.000 turistas por ano. Se estes dados estiverem corretos, a Gruta do Lago Azul recebeu em 2005 aproximadamente $65 \%$ dos turistas que foram à região - outro dado significativo.

Mas os dados ora apresentados devem ser compreendidos apenas como um alerta da importância dos atrativos espeleoturísticos em seu contexto regional. Pesquisas mais aprofundadas e específicas se fazem necessárias, para comprovar as evidências sinalizadas por meio destes números. O que se considera importante enfatizar é a indubitável relevância do espeleoturismo no contexto econômico de algumas regiões. Tomando-se como exemplo o caso do PETAR-SP, onde o ingresso de acesso ao Núcleo Santana custa R\$3,00 (três reais), somente em 2004 obteve-se uma renda bruta superior a $\mathrm{R} \$ 75.000,00$ (setenta e cinco mil reais). Este valor, entretanto, está muito abaixo do montante obtido no Abismo Anhumas, com um valor bruto aproximado de $\mathrm{R} \$ 270.000,00$ (duzentos e setenta mil reais) para o ano de 2005. Obviamente, trata-se de um empreendimento particular, que visa o lucro, mas que ao mesmo tempo consegue reverter o uso do patrimônio espeleológico em mais benefícios para a sua região, por meio da empregabilidade, de salários e da circulação de parte do capital recebido no comércio local.

É também importante ressaltar que os valores mencionados correspondem apenas aos ingressos gerados nos atrativos. Obviamente, estes turistas fazem uso das estruturas de hospedagem, alimentação, transportes e outros serviços turísticos e 
básicos, aumentando ainda a relevância deste tipo de atrativo em seu contexto de análise.

Esta relevância é maior ou menor dependendo da região do país. Recentemente, a região dos Parques Estaduais: Turístico do Alto Ribeira, Intervales e Caverna do Diabo - no Estado de São Paulo - teve todo seu fluxo turístico afetado, em função do fechamento das cavernas para a visitação, feito pelo CECAV, em março de 2008. A questão apresenta amargos prejuízos para as centenas de famílias que dependem do fluxo turístico local, que chegou praticamente a zero. Por outro lado, fica também uma questão conceitual: o turismo realizado na região mencionada deveria ser classificado como Ecoturismo ou espeleoturismo? Ou a fronteira conceitual nesse caso é demasiado tênue para uma resposta definitiva?

Por outro lado, não deixa de ser problemática a exclusão gerada pelos altos preços cobrados nos atrativos na região de Bonito. Essa premissa de certa forma fere os princípios da sustentabilidade social, pois elimina oportunidades dos menos abastados, repetindo nas cavernas o mesmo que ocorre em outros roteiros de turismo de natureza.

\section{Considerações finais e perspectivas para as pesquisas no tema}

O presente trabalho esboçou de forma geral alguns aspectos relevantes do espeleoturismo no Brasil, sobretudo ao que tange suas interfaces com o Ecoturismo enquanto base filosófica e como uma de suas principais motivações. No escopo desta análise, foram consideradas quatro dimensões presentes no espeleoturismo, em seu âmbito teórico e prático: a espeleológica, a territorial, a política e a econômicoecológica. Por certo, a abordagem utilizada não esgota o assunto e nem tampouco oferece um panorama geral do estado-da-arte do tema no Brasil. A contemplação das questões socioculturais, epistemológicas, conceituais, econômico-regionais e a Educação Ambiental, bem como o aprofundamento da questão política e uma análise mais detalhada se fazem necessárias para complementar o presente estudo, deixando ampla margem para a continuidade dos trabalhos sobre o tema e para instigar a comunidade acadêmica, técnica e científica a se engajarem na presente discussão.

Pela vertente espeleológica, foram analisadas as principais variáveis do ambiente cavernícola que interferem e recebem interferências no processo de visitação turística. $O$ destaque ficou para o confinamento espacial e a escuridão. A abrangência territorial também foi considerada. Estudos anteriores foram compilados, e atualizados por meio de dados de campo, apontando assim para um total de 175 cavernas com algum tipo de visitação espeleoturística no país. 
Quanto à análise das políticas para o setor, ressalta-se a falta de instrumentos e mecanismos políticos, técnicos e científicos mais focados no turismo e sua interface com a conservação ambiental. Poucos instrumentos e diretrizes legais fornecem apontamentos para que as práticas espeleoturísticas possam ser mais bem direcionadas. Se por um lado isto é positivo, por não criar regras excessivas e demasiadamente restritivas, por outro deixa uma incógnita no tocante às possibilidades de uso turístico conservacionista sustentável. Face ao exposto, percebe-se a expansão dos impactos negativos causados pela atividade no ambiente, e a situação paradoxal em termos de sustentabilidade que isso gera quando confrontado com a importância econômica dos roteiros existentes em seu contexto regional.

Os resultados ora apresentados validam a existência de um vasto campo de estudos, focado no planejamento e gestão do espeleoturismo. Entretanto, alerta-se por fim para a importância de que pesquisas mais específicas sejam feitas, no sentido de delimitar o espeleoturismo pela ótica do mercado, tendo por base também as preferências de consumo dos turistas. Assim, compreende-se que novos subsídios poderão ser encontrados para: a consolidação do espeleoturismo enquanto segmento emergente e à parte no arcabouço da segmentação do mercado turístico em um processo de subdivisão do Ecoturismo - enquanto motivação de viagem e especificidade de planejamento e gestão, mas não na forma de execução -; bem como para a formação de políticas públicas para o seu fomento e expansão sustentáveis.

\section{Referências}

ARIAS, M.C.; MESQUITA, C.A.B.; MÉNDEZ, J.; MORALES, M.E.; AGUILAR, N.; CANCINO, D.; GALLO, M.; RAMIREZ, C.; RIBEIRO, N.; SANDOVAL, E.; TURCIOS, M.. Capacidad de carga turística de las áreas de uso público del Monumento Nacional Guayabo, Costa Rica. Turrialba: Catie/WWF, 1999.

BOGGIANI, P.C. Por que Bonito é bonito? In: SCREMIN-DIAS, E., POTT, V.J., SOUZA, P.R.; HORA, R.C. Nos jardins submersos da Bodoquena: guia para identificação das plantas aquáticas de Bonito e região. Campo Grande: UFMS, 1999.

BOGGIANI, P.C.; SILVA, O.J.; GESICKI, A.L.D.; SALLES, L.O.; GALATI, E.; LIMA, M.M.E.R. Estudo de impacto ambiental da visitação turística do Monumento Natural Gruta do Lago Azul - Bonito, MS. Campo Grande: UFMS, 1999.

BRASIL Constituição da República Federativa do Brasil de 1988. Disponível em http:// www.planalto.gov.br/ccivil_03/Constituicao/Constitui\%C3\%A7ao.htm. Acesso em 23 abr. de 2008. 
BRASIL. Lei $n^{\circ} 9985$ de 18 de julho de 2000: Sistema Nacional de Unidades de Conservação. Brasília: Presidência da República, 2000. Disponível em: <https:// www.presidencia.gov.br/>. Acesso em 28 dez. 2005.

CIGNA, A.A. Environmental management of tourist caves - the examples of Grotta di Castellana and Grotta Grande del Vento, Italy. Environmental Geology, Heidelberg, v. 21, p. 173-180. 1993.

CIGNA, A.A. Monitoring of caves: conclusions and recommendations. Acta Carsologica, v. 31, n. 1, 2002. p. 175-177.

CIGNA, A.A.; BURRI, E. Development, management and economy of show caves. International Journal of Speleology, Bologna, v. 29 n. 01, p. 01-27, 2000.

CONAMA. Resolução CONAMA n 347 de 10 de setembro de 2004. Diário Oficial da União, Brasília, ed. 176, seção 01, p. 54. 13 set. 2004.

DIEGUES, A.C.S. O mito moderno da natureza intocada. 3.ed. São Paulo: Hucitec, 2000.

DOORNE, S. Caves, culture and crowds: carrying capacity meets consumer sovereignty. Journal of Sustainable Tourism, v. 8, n. 2, 2000. p. 116-130,

EPA. A lexicon of cave and karst terminology with special reference to environmental karst hydrology. Washington, DC: U.S. Environmental Protection Agency/EPA, 2002. Disponível em http://cfpub.epa.gov/ncea/cfm/recordisplay.cfm? deid=54964. Acesso em 19 jun. de 2006.

FIGUEIREDO, L.A.V. Cavernas brasileiras e seu potencial ecoturístico: um panorama entre a escuridão e as luzes. In: $\vee$ ASCONCELOS, F.P. (org.) Turismo e meio ambiente. Fortaleza: UECE, 1998.

GRADZIÒSKI, M.; HERCMAN, H.; NOWICKI, T.; BELLA, P. Dark coloured laminae within speleothems as an indicator of the prehistoric man activity: case study from Domica Cave (Slovakia), preliminary results. In: International Congress of Speleology, 13, 2001. Brasília. Proceeedings. Brasília: SBE, Vol. 1. 2001. pp.125-9.

HILL, C.A.; FORTI, P. The classification of cave minerals and speleothems. International Journal of Speleology, Bologna, v. 24, n. 01, 1995, p. 77-82, .

IBAMA. Instrução normativa n. 100 de 5 de junho de 2006. Diário Oficial da União, Brasília, ed. 107, seção 1, 2006. p. 64-6. 6 jun.

LINO, C.F. Manejo de cavernas para fins turísticos: base conceitual e metodológica. São Paulo: s.ed., 1988. Mimeo. 
LINO, C.F. Cavernas: o fascinante Brasil subterrâneo. 2.ed. rev e atual. São Paulo: Gaia, 2001.

LINO, C.F. Cavernas brasileiras. Brasília: MRE, s.d. Disponível em http:// www.mre.gov.br/cdbrasil/itamaraty/web/port/meioamb/ecossist/caverna/index.htm. Acesso em 30.maio.2007.

LOBO, H.A.S. Considerações preliminares para a reestruturação turística da Caverna de Santana - PETAR, Iporanga, SP. In: Congresso Brasileiro de Espeleologia, 28, 2005, Campinas. Anais. Campinas: SBE, 2005. p. 77-87.

LOBO, H.A.S. Caracterização dos impactos ambientais negativos do espeleoturismo e suas possibilidades de manejo. In: Seminário de Pesquisa em Turismo do Mercosul, 4, 2006a, Caxias do Sul. Anais. Caxias do Sul: Universidade de Caxias do Sul, 2006a. 01-15.

LOBO, H.A.S. O lado escuro do paraíso: espeleoturismo na Serra da Bodoquena. Aquidauana: UFMS, 2006b. Dissertação (Mestrado em Geografia), Departamento de Geociências, Universidade Federal de Mato Grosso do Sul. 2006b.

LOBO, H.A.S. Método para avaliação do potencial espeleoturístico do Parque Nacional da Serra da Bodoquena, MS. Caderno Virtual de Turismo, Rio de Janeiro, v. 7, n. 3, 2007. p. 99-110.

LOBO, H.A.S.; ASMUS, R.M.F. Proposta metodológica para classificação do potencial espeleoturístico. In: Congresso Brasileiro de Espeleologia, 29, 2007, Ouro Preto, MG. Anais. Ouro Preto: SEE/SBE, 2007. p. 1-4.

LOBO, H.A.S.; PILONETO, A.; BENITES, G.; RANGEL, M.C.R.; SILVA, M.C.F.; MELO, M.E.; FERREIRA, R.P. Reflexões e propostas para as políticas públicas de espeleoturismo no Brasil. Global Tourism, Ourinhos, v. 3, jun. 2006. Disponível em $<$ http://www.periodicodeturismo.com.br/site/principal/index.php>. Acesso em 14 jun. 2006.

LOBO, H.A.S.; LOURENÇÃO, M.L.F.; AMORIM, A.S.; CUNHA, F.M.; RAMOS, J.C.; LIMA, K.M.; CAMARGO, R.R.; ZAGO, S. Variáveis e indicadores para análise do potencial espeleoturístico. In: Congresso Brasileiro de Espeleologia, 29, 2007, Ouro Preto, MG. Anais. Ouro Preto: SEE/SBE, 2007. p. 1-4.

MARRA, R.J.C. Espeleo turismo: planejamento e manejo de cavernas. Brasília: WD Ambiental, 2001.

MARTÍNEZ-ARKARAZO, I.; ANGULO, M.; MADARIAGA, J.M.; LES, J. Investigación preliminar sobre un innovador proceso de limpieza de la microflora de origen antropogénico en la Cueva de Pozalagua (Karrantza, Biscaia). In: Congreso Español 
de Cuevas Turísticas y Panel de Expertos de la International Show Caves Association, 1, Lekunberri, 2005. Disponível em http:// www.sociedadalfonsoantxia.org/hongos2.pdf. Acesso em 08 mar. 2006.

NOGUEIRA, M.K.R. Percepção da qualidade de serviços em espeleoturismo: a Gruta do Maquine. Belo Horizonte: UNA, 2006. Dissertação (Mestrado em Turismo e Meio Ambiente), Centro Universitário UNA. 2006.

PULIDO-BOSCH, A.; MARTÍN-ROSALES, W.; LÓPEZ-CHICANO; M., RODRÍGUEZNAVARRO, M.; VALLEJOS, A. Human impact in a tourist karstic cave (Aracena, Spain). Environmental Geology, Heidelberg, v. 31, n. 3-4, 1997. p. 142-9, jun.

RASTEIRO, M.A. Mais um projeto de lei para as cavernas. SBE Notícias, Campinas, n. 80, 2008a. p. 2.

RASTEIRO, M.A. Só dez cavernas tem plano de manejo. SBE Notícias, Campinas, $n$. 81, 2008-b. p. 1.

RUSCHMANN, D. M. Turismo e planejamento sustentável: a proteção do meio ambiente. 11.ed. Campinas: Papirus, 2004.

SCALEANTE, J.A.B. Avaliação do impacto de atividades turísticas em cavernas. Campinas: UNICAMP, 2003. Dissertação (Mestrado em Geociências), Instituto de Geociências, Universidade Estadual de Campinas. 2003.

SONG, L.; WEI, X.; LIANG, F. The influences of cave tourism on $\mathrm{CO}_{2}$ and temperature in Baiyun Cave, Hebei, China. International Journal of Speleology, Bologna, v. 29, n. 01,2000 . p. $77-87$,

SPOLADORE, A. A geologia e a geoespeleologia como instrumentos de planejamento para o desenvolvimento do turismo: o caso de São Jerônimo da Serra/PR. Rio Claro: UNESP, 2006. Tese (Doutorado em Geociências e Meio Ambiente), Instituto de Geociências e Ciências Exatas, Universidade Estadual Paulista, 2006.

TRAJANO, E.; BICHUETTE, M.E. Biologia subterrânea. São Paulo: Redespeleo, 2006.

TRAVASSOS, L.E.P.; TRAVASSOS, E.G.; TRAVASSOS, L.P.; RODRIGUES, E.R. Ensaio exploratório sobre a percepção do endocarste e do exocarste de alunos do ensino médio. Espeleologia, Ouro Preto, n. 12, 2007. p. 30-35. 
Heros Augusto Santos Lobo: UNESP - Programa de Pós-Graduação em Geociências e Meio Ambiente.

E-mail: heroslobo@hotmail.com.

Link para o currículo Lattes: http://lattes.cnpq.br/9405961078398915

José Alexandre de Jesus Perinotto: UNESP - Depto. de Geologia Aplicada, Instituto de Geociências e Ciências Exatas/IGCE.

E-mail: perinoto@rc.unesp.br

Link para o currículo Lattes: http://lattes.cnpq.br/1994317879078816

Paulo César Boggiani : USP - Instituto de Geociências - Departamento de Geologia Sedimentar e Ambiental,

E-mail: boggiani@usp.br

Link para o currículo Lattes: http://lattes.cnpq.br/0326579897116378

Data de submissão: 03 de maio de 2008

Data de aceite: 21 de agosto de 2008 